NASA/TM-2006-214243

\title{
Status of NASA's Advanced Radioisotope Power Conversion Technology Research and Development
}

Wayne A. Wong, David J. Anderson, Karen L. Tuttle, and Roy C. Tew

Glenn Research Center, Cleveland, Ohio 


\section{NASA STI Program . . . in Profile}

Since its founding, NASA has been dedicated to the advancement of aeronautics and space science. The NASA Scientific and Technical Information (STI) program plays a key part in helping NASA maintain this important role.

The NASA STI Program operates under the auspices of the Agency Chief Information Officer. It collects, organizes, provides for archiving, and disseminates NASA's STI. The NASA STI program provides access to the NASA Aeronautics and Space Database and its public interface, the NASA Technical Reports Server, thus providing one of the largest collections of aeronautical and space science STI in the world. Results are published in both non-NASA channels and by NASA in the NASA STI Report Series, which includes the following report types:

- TECHNICAL PUBLICATION. Reports of completed research or a major significant phase of research that present the results of NASA programs and include extensive data or theoretical analysis. Includes compilations of significant scientific and technical data and information deemed to be of continuing reference value. NASA counterpart of peer-reviewed formal professional papers but has less stringent limitations on manuscript length and extent of graphic presentations.

- TECHNICAL MEMORANDUM. Scientific and technical findings that are preliminary or of specialized interest, e.g., quick release reports, working papers, and bibliographies that contain minimal annotation. Does not contain extensive analysis.

- CONTRACTOR REPORT. Scientific and technical findings by NASA-sponsored contractors and grantees.
- CONFERENCE PUBLICATION. Collected papers from scientific and technical conferences, symposia, seminars, or other meetings sponsored or cosponsored by NASA.

- SPECIAL PUBLICATION. Scientific, technical, or historical information from NASA programs, projects, and missions, often concerned with subjects having substantial public interest.

- TECHNICAL TRANSLATION. Englishlanguage translations of foreign scientific and technical material pertinent to NASA's mission.

Specialized services also include creating custom thesauri, building customized databases, organizing and publishing research results.

For more information about the NASA STI program, see the following:

- Access the NASA STI program home page at http://www.sti.nasa.gov

- E-mail your question via the Internet to help@sti.nasa.gov

- Fax your question to the NASA STI Help Desk at 301-621-0134

- Telephone the NASA STI Help Desk at 301-621-0390

- Write to:

NASA STI Help Desk

NASA Center for AeroSpace Information 7121 Standard Drive Hanover, MD 21076-1320 
NASA/TM-2006-214243

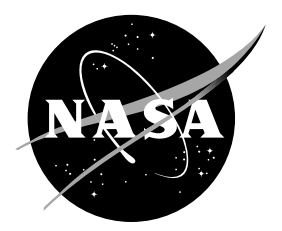

\section{Status of NASA's Advanced Radioisotope Power Conversion Technology Research and Development}

Wayne A. Wong, David J. Anderson, Karen L. Tuttle, and Roy C. Tew

Glenn Research Center, Cleveland, Ohio

Space Technology and Applications International Forum (STAIF-2006)

sponsored by the University of New Mexico's Institute for Space and Nuclear Power Studies (UNM-ISNPS)

Albuquerque, New Mexico, February 12-16, 2006

National Aeronautics and

Space Administration

Glenn Research Center

Cleveland, Ohio 44135 


\section{Acknowledgments}

The results and findings presented here are based on work funded by the National Aeronautics and Space Administration (NASA) under the Radioisotope Power Conversion Technology NASA Research Announcement NRA 02-OSS-01 issued through the Science Mission Directorate. The authors acknowledge the technical achievements by the respective contractor teams, and the contributions of the NASA contract and technical monitors.

Trade names and trademarks are used in this report for identification only. Their usage does not constitute an official endorsement, either expressed or implied, by the National Aeronautics and Space Administration.

Level of Review: This material has been technically reviewed by technical management.

Available from

NASA Center for Aerospace Information 7121 Standard Drive

Hanover, MD 21076-1320
National Technical Information Service 5285 Port Royal Road Springfield, VA 22161 


\title{
Status of NASA's Advanced Radioisotope Power Conversion Technology Research and Development
}

\author{
Wayne A. Wong, David J. Anderson, Karen L. Tuttle, and Roy C. Tew \\ National Aeronautics and Space Administration \\ Glenn Research Center \\ Cleveland, Ohio 44135
}

\begin{abstract}
NASA's Advanced Radioisotope Power Systems (RPS) development program is funding the advancement of next generation power conversion technologies that will enable future missions that have requirements that can not be met by either the ubiquitous photovoltaic systems or by current Radioisotope Power Systems (RPS). Requirements of advanced radioisotope power systems include high efficiency and high specific power (watts/kilogram) in order to meet mission requirements with less radioisotope fuel and lower mass. Other Advanced RPS development goals include long-life, reliability, and scalability so that these systems can meet requirements for a variety of future space applications including continual operation surface missions, outer-planetary missions, and solar probe. This paper provides an update on the Radioisotope Power Conversion Technology Project which awarded ten Phase I contracts for research and development of a variety of power conversion technologies consisting of Brayton, Stirling, thermoelectrics, and thermophotovoltaics. Three of the contracts continue during the current Phase II in the areas of thermoelectric and Stirling power conversion. The accomplishments to date of the contractors, project plans, and status will be summarized.
\end{abstract}

\section{Introduction}

NASA has a history of successful space flight missions that depended on radioisotope fueled power systems. These Radioisotope Power Systems (RPS) use the heat generated from the decay of radioisotope material, and convert the heat into useful electrical power. RPS is most attractive in applications where photovoltaics are not optimal such as for deep space applications where the solar flux is too low or for extended surface applications such as those on Mars or the Moon where the day/night cycle, settling of dust and life requirements limit the usefulness of photovoltaics. Past RPS systems utilizing thermoelectric power conversion have proven to be highly reliable, longlived designs. The U.S. has flown twenty-one space missions that have successfully used Radioisotope Thermoelectric Generators (RTG), which incorporate General Purpose Heat Source (GPHS) modules. While a proven reliable design, the GPHS-RTG has a relatively low power conversion efficiency of about 7 percent, a BOM system specific power of about $5 \mathrm{~W} / \mathrm{kg}$, and is limited to vacuum environment applications.

The objective of the National Aeronautics and Space Administration's (NASA) Radioisotope Power Systems (RPS) Program is to develop power systems and technologies that will enable or improve the effectiveness of future space science missions. The NASA Science Mission Directorate, recognizing the need for reestablishing and improving RPS, is currently developing two flight systems, the Multi-Mission RTG (MMRTG) and the Stirling Radioisotope Generator (SRG) (Schmidt, Wiley, and Richardson, 2005). NASA anticipates future mission requirements that go beyond the capabilities of MMRTG and SRG requiring advanced RPSs that offer better performance and higher specific power. This paper describes NASA's Radioisotope Power Conversion Technology (RPCT) Project, the purpose of which is to improve future RPS by developing conversion technologies applicable to these systems that provide higher efficiency and specific power. The paper provides background on the RPCT Project, and describes in greater detail the current status.

\section{Radioisotope Power Conversion Technology (RPCT) Project}

To develop technologies applicable to advanced RPS, NASA released NASA Research Announcement (NRA) 02-OSS-01 entitled "Radioisotope Power Conversion Technology" (RPCT) soliciting proposals for development of next generation power conversion technology (NASA, 2002). The objective of the RPCT Project, managed by NASA Glenn Research Center (GRC), is to advance the development of radioisotope power conversion technologies to provide higher efficiency and specific power than the state-of-practice GPHS/RTG. Other general Advanced RPS 
goals include safety, long-life (14 years, with well understood degradation), reliability, scalability, multi-mission capability (vacuum and atmosphere), resistance to radiation (from the GPHS or potential mission environments), and minimal interference with the scientific payload. The emphasis of the RPCT NRA contracts is the development of the power conversion technology (converting heat to electric power). Many auxiliary elements of the RPS are considered to be beyond the scope of this NRA, such as radiators, GPHS, insulation, etc. and are not included in this technology development effort. It is anticipated that future development efforts in collaboration with DOE will encompass development of the non-converter components and integration of these components with the power conversion system.

Phase I of the RPCT Project was initiated in the summer/fall of calendar year 2003 when ten NRA contracts were awarded. The selections included five larger "Development" contracts using more mature technology (Technology Readiness Level (TRL) 3 to 5) and five smaller "Research" contracts using less mature technology (TRL 1 to 3). The selections included a broad range of conversion technologies including free-piston Stirling (Wood, et al., 2006), turbo-Brayton (Zagarola, et al., 2005), thermoelectrics (TE) (Flanders, et al., 2005), and thermophotovoltaics (TPV) (Crowley, et al., 2005 and Horne, et al., 2005). Each RPCT NRA contract had a period of performance of up to three years, divided into three one-year phases, with options to continue the following phase after the conclusion of the prior phase. In July/August 2004, an annual review was conducted of all ten Phase I RPCT NRA contracts. The Phase I review committee included personnel from NASA Headquarters, GRC, Jet Propulsion Laboratory (JPL), and The Department of Energy (DOE) supported by Orbital Sciences Corporation. Based on the results of the review, a decision was made to continue seven of the ten contracts into Phase II, Phase II started in the November 2004 to January 2005 timeframe. However, due to a severe RPS Program budget reduction in January of 2005, four more of the Phase II contracts were terminated and only three of the Phase II contracts continue as of this writing. Funding for Phase I of all 10 RPCT contracts totaled 12.4 million, while the reduced funding for the three Phase II contracts is 5.4 million. An overview at the beginning of Phase I was presented by Wong, (2004), the status of the Phase I accomplishments was presented by Anderson, (2005), and a status of the efforts which started Phase II was presented by Anderson, Wong, and Tuttle, (2005). The following provides a current status of the work being performed as part of the three on-going Phase II RPCT NRA contracts led by Sunpower, Cleveland State University, and Massachusetts Institute of Technology, respectively.

\section{Advanced Stirling Convertor Development}

Sunpower, Inc. (Athens, OH) is leading a team consisting of Pratt and Whitney Rocketdyne, Cleveland State University (CSU), University of Minnesota (UMN), and several consultants to demonstrate an Advanced Stirling Converter (ASC) with significant improvements over 1st-generation flight systems and to achieve converter efficiency of $>30$ percent and a system specific power of $\geq 8 \mathrm{~W} / \mathrm{kg}$. The Sunpower free-piston Stirling contract is the only remaining higher TRL Development effort that is continuing through Phase II of the RPCT Project. The key technologies included in the ASC design are hydrostatic gas bearings, moving magnet linear alternators, high temperature heater head materials and fabrication techniques, high temperature high porosity regenerators, high frequency operation, and a controller with active power factor correction. The expected efficiency of the ASC is $\sim 40$ percent (AC power out/heat in), with a design output power of $88 \mathrm{We} \mathrm{AC}$ with an engine/alternator specific power of about $90 \mathrm{We} / \mathrm{kg}$ making feasible a projected RPS specific power of $\sim 8 \mathrm{~W} / \mathrm{kg}$. The charge pressure of the convertor is $3.5 \mathrm{MPa}$, and the frequency is $105 \mathrm{~Hz}$ Sunpower's Frequency Test Bed (FTB) Stirling convertor was designed, fabricated, and was made operational within the first five months of Phase I to allow frequency and advanced component investigations. Testing of the FTB would provide guidance on the design of the ASC. The FTB performance has surpassed project efficiency goals having demonstrated 36 percent conversion efficiency (AC power out/heat in) at operating temperatures of $650{ }^{\circ} \mathrm{C}$ hot end and $30^{\circ} \mathrm{C}$ cold end with output power of $80 \mathrm{We}$. These temperatures represent a temperature ratio of 3 , which is similar to the ASC which will operate at higher temperatures of 850 and $90^{\circ} \mathrm{C}$. ASC-1 (see fig. 1) was designed during Phase I and four of these non-hermetically sealed units will be built during the current Phase II. Two of these units will operate in a dynamically opposed low vibration configuration. Launch vibration testing and component reliability testing is also planned for Phase II. Phase III will involve the development of the ASC-2 which is a hermetically sealed design. The ASC is expected to produce $88 \mathrm{We} \mathrm{AC}$ at about 40 percent conversion efficiency assuming $220 \mathrm{~W}$ thermal input from the radioisotope heat source (minus insulation losses). 

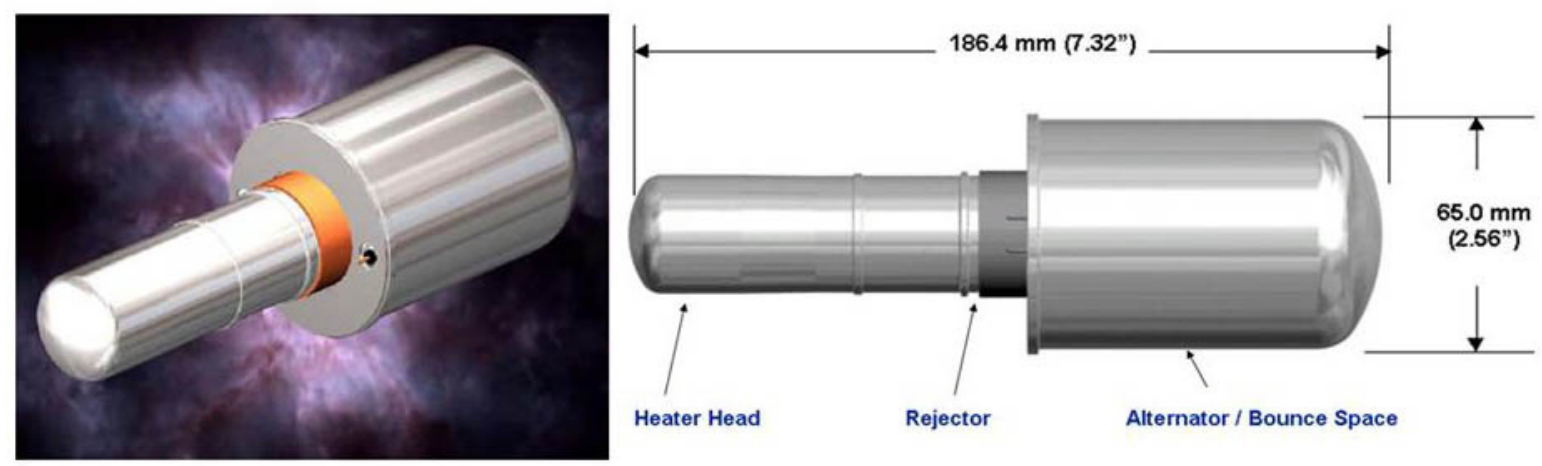

Figure 1.- Sunpower Advanced Stirling Convertor (ASC) artist concepts.

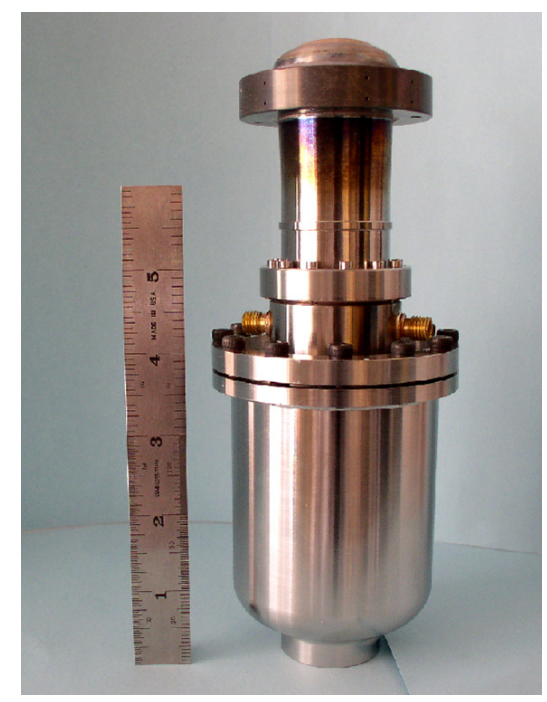

Figure 2.--Sunpower advanced stirling convertor (ASC-1a) including an all Mar-M-247 heater head allowing $850^{\circ} \mathrm{C}$ operation.

The ASC is designed with an advanced $850{ }^{\circ} \mathrm{C}$ heater head using Mar-M-247 which is to be provided by subcontractor Pratt and Whitney Rocketdyne. Prior to the selection of Mar-M-247, a variety of candidate high temperature materials was considered including materials that were being investigated and recommended by NASA GRC. For the 14 year life, high temperature requirements of the ASC, creep strength for the thin walled heater head pressure vessel is paramount. In addition to reviewing the data from creep testing conducted by NASA, the ASC team also conducted thin sample creep testing of Mar-M-247 during Phase I. Analysis indicates the projected 1 percent creep of the heater head over 14 years has no impact on ASC performance. The heater head material processing strategy was developed which included a number of critical joints between Mar-M-247 and other materials including diffusion bonding to Nickel 201, and inertial welding to Inconel 718. A variety of coupon, joining, and processing tests were carried out during Phase I and Phase II for risk mitigation purposes in using these materials and processing techniques.

The focus of the current Phase II effort is the development of the ASC-1, which is a non-hermetic design suited for laboratory development. The first half of Phase II included the fabrication and assembly of the ASC-1, shown in figure 2, which was completed and in operation by September 2005 (Wood, et al., 2006). At the time of this writing full temperature testing at $850^{\circ} \mathrm{C}$ had not yet been conducted. Testing to date indicates that the ASC-1, which still requires some dynamics optimization, is operating at approximately 38 percent conversion efficiency (AC out/heat input). These test results provide confidence that the design predications of $88 \mathrm{We} \mathrm{AC}$ power output and $\sim 40$ percent conversion efficiency is achievable at $850{ }^{\circ} \mathrm{C}$ hot end and $90^{\circ} \mathrm{C}$ cold end temperatures. 
In addition to the development of the convertor hardware, significant effort during Phase I and Phase II also involved reliability studies, component testing, advanced component investigations, and thermodynamic loss investigations. As an example, during Phase I, displacer losses were studied both analytically via CFD by CSU and through component testing by Sunpower to allow a reduction in the number of baffles required in the ASC displacer. The impact of this work manifests as a cost savings (fewer parts), reduced fabrication risk to the hardware (simplifying manufacturing), and higher reliability design (lower part count) with no impact on performance.

As part of the reliability assessment, during Phase II, a Hot Alternator Test Rig (HATR) was developed to characterize the ASC linear alternator performance at elevated temperatures and then to destructively test the alternator to identify temperature induced failure mechanisms. This ongoing work will provide valuable information on the margins in the alternator design and will provide input to the ongoing reliability assessment.

The ASC regenerator continues to be an area of development during Phase II, including Large-Scale Mock-Up (LSMU) testing conducted by UMn which will provide data on the near wall and jetting characteristics of the regenerator. Processing, fabrication, and oxidation of this critical component continues to be an area of investigation by the Sunpower team with support from GRC, focusing on the use of high temperature oxidation resistant material.

Accomplishments and Benefits of the Sunpower Advanced Stirling Convertor development effort:

- Phase I FTB demonstration surpassed performance goal demonstrating 36 percent conversion efficiency

- Phase II ASC-1 a completed and operational; testing to date at lower than design temperature provides encouraging results that design performance goals ( $88 \mathrm{We} \mathrm{AC}, 40$ percent efficiency) will be met later in Phase II

- Projected ASC performance and mass leads to significantly higher RPS specific power of $\geq 8 \mathrm{~W} / \mathrm{kg}$ enabling or enhancing future mission capabilities

- Success of this NASA sponsored technology is spinning-off into potential DOD applications

\section{Stirling Regenerator Microfabrication Research}

Cleveland State University (CSU, Cleveland, $\mathrm{OH}$ ) leads this research contract to develop micro-fabricated Stirling regenerators that offer structural robustness and improved thermal and flow performance, and to characterize a prototype regenerator in an engine. Projections indicate that the microfabricated regenerator may result in 6 to 9 percent higher power for an optimized Stirling convertor. The benefits of the advanced regenerator are not only to improve performance, but also improved structural robustness, reliability, manufacturability and an ordered geometry that lends itself to modeling and analysis. The CSU team includes University of Minnesota, Gedeon Associates, Sunpower, Infinia Corp. (formerly, Stirling Technology Company), and International Mezzo Technologies.

The Stirling Regenerator Microfabrication research effort has developed a new involute-foil matrix geometry that has precisely defined geometrical features (no pore scale randomness as in random fiber and wire screen materials), structured to reduce regenerator pressure drop while maintaining good heat transfer characteristics (Ibrahim, et al., 2005). Fabrication techniques require fine sub- $100 \otimes \mathrm{m}$ scale features in a regenerator that is of $100 \mathrm{~mm}$ scale. Several geometries were considered (lenticular, honeycomb, involute, and modified involute) as well as a host of microfabrication techniques and vendors before a unique geometry and vendor using a combined LIGA-EDM process was selected. The selected regenerator design is composed of a stack of hundreds of 265 冈m thick foil disks, each disk having a series of involute patterns on them. The design utilizes disks assembled with involutes in an alternating pattern as shown in figure 3(a), mixing the flow resulting in improved heat transfer.

The CSU Regenerator Microfabrication NRA Contract is making progress in three major areas: 1) fabrication of involute-foil regenerators, 2) Empirical and Analytical heat transfer and pressure drop characterization using LargeScale-Mock-Up (LSMU) and CFD analysis, and 3) actual-scale oscillating-flow rig testing of the involute foils. More details on the Phase I accomplishments can be found in Ibrahim, et al., (2005). Mezzo is currently in the process of fabricating Nickel involute-foil regenerators for testing in the NASA/Sunpower oscillating-flow test rig. Mezzo expects to complete this microfabrication effort by the end of December 2005 via a LIGA (X-ray lithography) approach. An Xray mask that allows simultaneous production of 19 microfabricated disks is shown in figure 3(b). The resulting disks will be used for testing in the oscillating-flow rig to experimentally determine the friction-factor and heat-transfer characteristics of a representative regenerator stack. If testing in the oscillating-flow rig provides positive results, the next phase of the effort would be to fabricate a full regenerator using stainless-steel elements for testing in a Stirling engine. These would be fabricated via a combined LIGA-EDM technique. Figure 3(c) shows the details of a portion of a stainless-steel involute foil disk that was fabricated by Mezzo via the LIGA-EDM approach as a proof of concept. To complete Phase II, the regenerator disks fabricated by Mezzo will be tested in the oscillating-flow test rig by Sunpower and analyzed by Gedeon Associates in the January to March 2006 time period. 


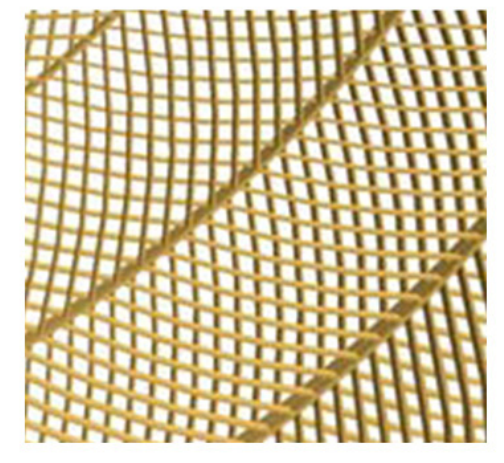

(a) Two Involute Disks Stacked in Alternating Sequence.

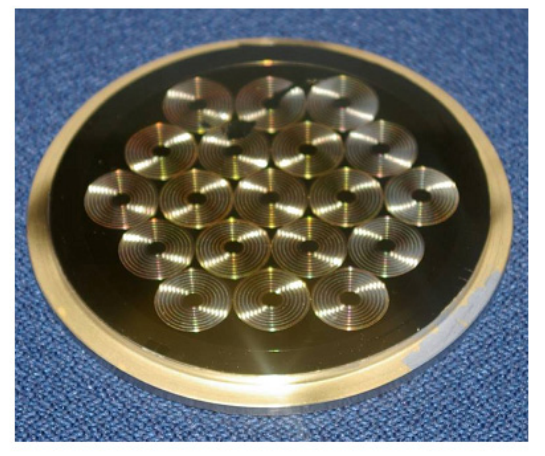

(b) X-ray Mask.

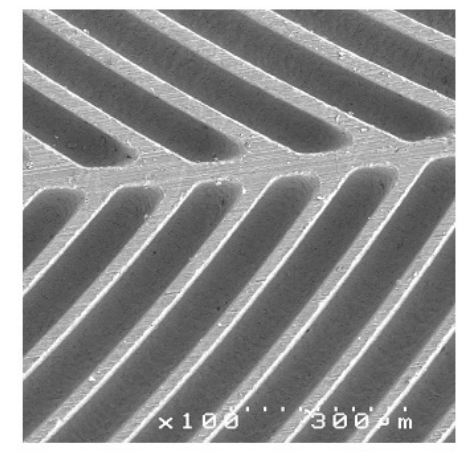

(c) Stainless Steel Involute Foil.

Figure 3.-Design and hardware from the CSU regenerator microfabrication contract.

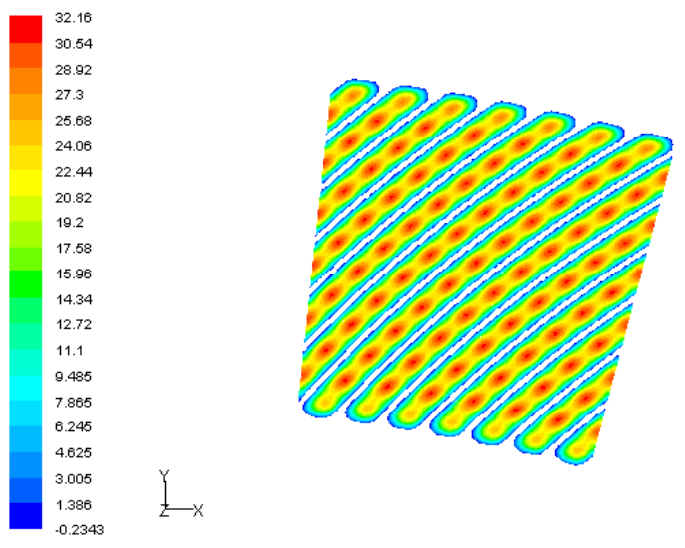

(a) CFD Calculated Velocity Contours in portion of Involute Foil.

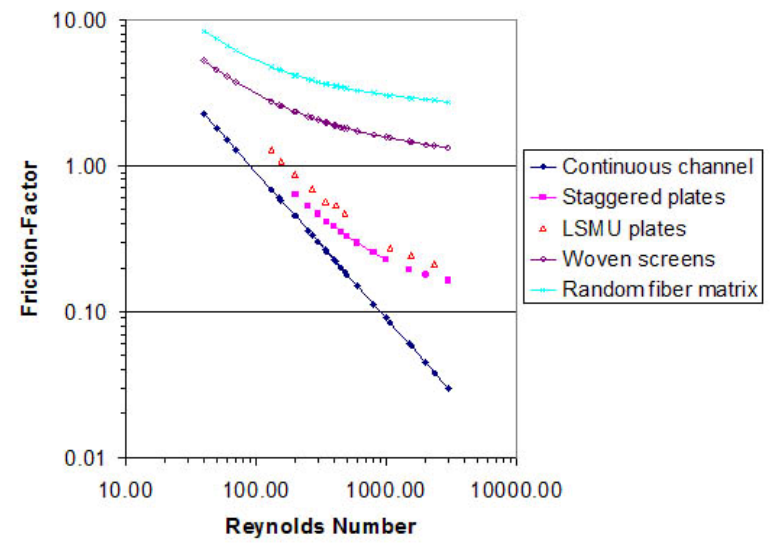

(b) Darcy-Weisbach Friction-Factor versus Reynolds Number for Different Geometries.

Figure 4.-Analytical predictions from the CSU regenerator microfabrication contract.

To determine the figure of merit (ratio of heat transfer and pressure drop characteristics) for the involute foil regenerator, heat-transfer measurements and CFD heat-transfer calculations will be made. Figure 4(a) shows CFD determined velocity contours inside the flow channels of an involute foil disk. Such velocity results were used in calculating friction-factors. The CFD will also provide support to the analysis of the oscillating-flow rig results. Meanwhile testing of a Large-Scale-Mock-Up (LSMU) of the involute foils, and CFD simulation of them, is ongoing at the University of Minnesota (UMN) and Cleveland State University (CSU), respectively. Figure 4(b) shows UMN experimental friction-factor results for the LSMU involute-foil elements compared with friction-factors for (1) continuous channels which have the same aspect ratio as the tested foils, (2) staggered parallel-plates, (3) woven-screen matrices, and (4) random-fiber matrices. The LSMU testing offers the encouraging result that, while the involute-foil pressure drop will not be quite as low as if the channels were continuous (instead of interrupted from one disk to the next), the pressure drop will be substantially less than for wire-screens and much less than for random fibers which represent the state-of-the art regenerators. However, the interruption of the flow path from one disk to the next will improve radial heat transfer and decrease axial heat transfer (both desirable changes) relative to that of the continuous channels. Regenerator operation is expected to be close to the low end of the Reynolds operating range shown in figure 4 (b) $(\sim$ Reynolds No. $=100)$. CSU CFD calculations of involute foil friction-factors seemed consistent with the measurements. 
Accomplishments and Benefits of the CSU Stirling Regenerator Microfabrication research effort:

- Development of an advanced regenerator offering improved structural robustness for higher reliability, controlled manufacturability, and improved Stirilng convertor performance (projected 6 to 9 percent power increase)

- Permits use of progressive materials for strength and corrosion resistance

- Broad benefits - technology can be used in Stirling cryocooler regenerators and microscale heat exchangers

\section{Thermoelectric (TE) Nanocomposite Research}

Massachusetts Institute of Technology (MIT), acting as the prime contractor, has teamed with Boston College (BC) and the Jet Propulsion Laboratory (JPL) on this research contract to design, synthesize, and develop Si-Ge nanocomposites with an improved figure-of-merit (ZT) over bulk SiGe. This nanostructure technology has the potential to increase the material's performance by increasing the Seebeck coefficient and reducing the thermal conductivity without affecting the electrical conductivity. The effect of these improvements would be to provide a net gain in the ZT that enhances the thermoelectric performance. The goal of this effort is to demonstrate ZT of $\sim 2.0$ at $900 \mathrm{~K}$ with efficiency of 12 to 14 percent. Another goal of this contract is to synthesize bulk nanocomposites in a large-scale manufacturing process such that large numbers of thermoelectric couples could be produced at a relatively low cost. Specific tasks of this research activity include nanostructure synthesis, structural characterization, thermoelectric properties characterization and modeling of the nanocomposites.

During Phase II of this effort, progress was made in three areas: 1) Synthesis and structural characterization of both nanoparticles and nanocomposite samples, 2) Thermoelectric property measurements of the nanocomposite materials, and 3) modeling and simulation of the nanoparticles and the nanocomposites they formed. Synthesis of nanoparticles was advanced using three different methods (see fig. 5): 1) the wet chemistry method carried out at Boston College, which has a high potential for scale-up for making bulk quantities, 2) the ball milling method that has been under development at JPL, which also has potential for scale-up, and finally 3 ) the inert gas condensation method under development at the University of Illinois at Champaign/Urbana. These nanoparticles were hot pressed into nanocomposite samples using a newly acquired Plasma Pressure Compaction $\left(\mathrm{P}^{2} \mathrm{C}\right)$ apparatus at Boston College, and in a hot press apparatus at JPL. Mechanically strong bulk size samples of nanocomposite materials were produced both at JPL and at Boston College that also preserved the nanostructure of the Si and Ge.

Nanocomposite samples were characterized at room temperature for screening and promising samples were then characterized at high temperatures (up to $500 \mathrm{~K}$ at MIT and up to $1275 \mathrm{~K}$ at JPL). The thermal conductivity measurements of nanocomposite samples produced by both the mechanical alloying (MA) and $\mathrm{P}^{2} \mathrm{C}$ methods indicate significantly lower thermal conductivity than any previously reported on bulk alloys. (Lee et al., 2005) A plot of temperature dependence of ZT for a variety of p-type thermoelectric samples (fig. 6) shows very encouraging results. For temperatures up to $1050 \mathrm{~K}$, the best nanocomposite samples have higher ZT (better performance characteristics) than that of RTG SiGe and samples from SP-100 and JIMO.

During Phase II, modeling advances were also made. MIT carried out calculations of the in-plane thermal conductivity of nanowires and nanowire composites by solving the two-dimensional Boltzmann transport equation for a variety of core-shell structures. These detailed calculations contributed to the selection of nanoparticles rather than nanowires as the basic nano-sized structured unit to be used in preparing the nanocomposite materials. Modeling in combination with experimental data shows that enhancements in ZT can be achieved in nanocomposite materials through both a reduction in the thermal conductivity and an increase in power factor on the same samples and within a common temperature range.

Accomplishments and Benefits of the MIT Thermoelectric Nanocomposites research:

- Nanostructures offer promise for increasing ZT and conversion efficiency by more than a factor of 2

- Synthesis of bulk nanostructured materials enable practical realization of this potential

- Detailed modeling of bulk nanostructures and nanocomposites guides materials design and enables further optimization 


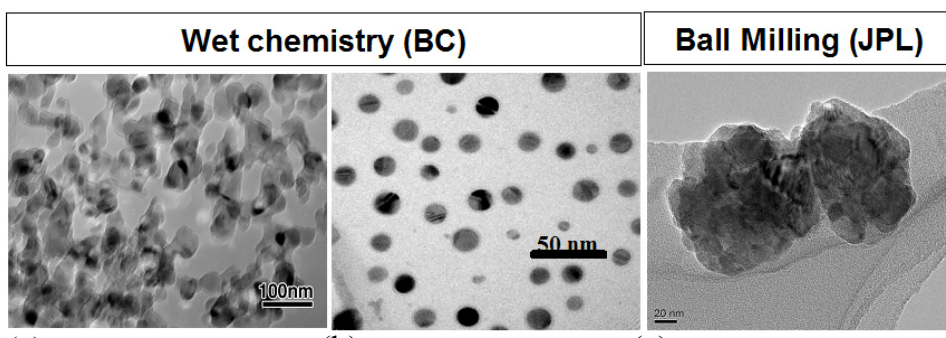

(a) Si Nanoparticles (b) Ge Nanoparticles

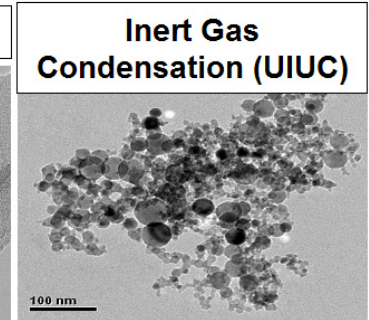

(d) Si Nanoparticles

Figure 5.- $\mathrm{Si}$ and Ge nanoparticles produced under the MIT contract.

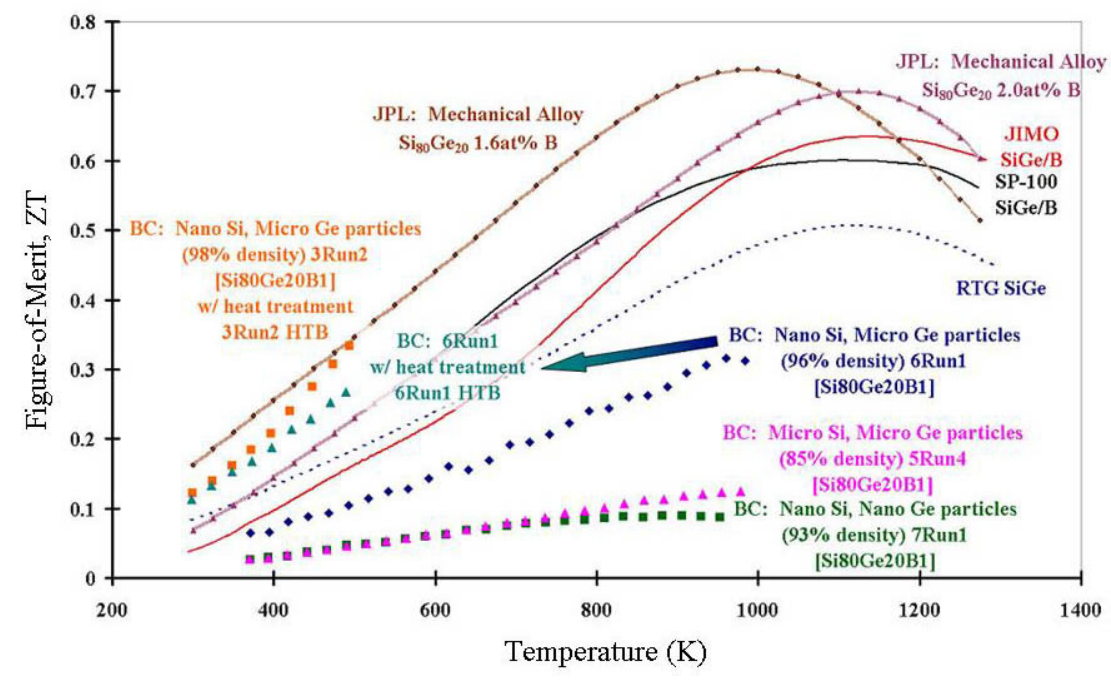

Figure 6.-Plot of ZT versus temperature for mechanical alloy and $\mathrm{P}^{2} \mathrm{C}$ hot pressed nanocomposites as compared to the NASA flight RTG

SiGe bulk materials and a variety of JIMO test samples.

\section{Conclusion}

NASA has successfully used radioisotope fuel to power numerous past missions in applications where PV arrays are not practical. Next generation conversion technologies suitable for future RPS, with higher efficiency, higher specific power (W/kg), long life, high reliability, scalability, and multi-mission capability are being developed under contracts awarded as part of the Radioisotope Power Conversion Technology Project. Results from the three on-going Phase II RPCT NRA contracts in the areas of Stirling and thermoelectric (TE) power conversion technology have been summarized. Emphasis of these advanced conversion technology development and research efforts is on improving performance, increasing system specific power, and providing reliability for long life. These attributes allow for improved RPS systems that will require less plutonium fuel, are more cost effective, have lower waste heat rejections requirements, and will enable or enhance future mission capability. These advanced RPS systems will provide NASA with attractive power system options for future Space Science and Exploration missions such as outer planetary exploration and Lunar and Mars exploration missions. 


\section{References}

1. Anderson, D.J., "NASA Radioisotope Power Conversion Technology NRA Overview," in proceedings of Space Technology and Applications International Forum (STAIF-2005), edited by M. El-Genk, AIP Conference Proceedings 746, American Institute of Physics, Melville, New York, 2005.

2. Anderson, D.J., Wong, W.A., and Tuttle, K.L., "An Overview and Status of NASA's Radioisotope Power Conversion Technology NRA," in Proceedings of the 3rd International Energy Conversion Engineering Conference (IECEC 2005), AIAA-2005-5713, Providence, RI, 2005.

3. Crowley, C.J., Elkouh, N.A., Murray, S.L., Chubb, D.L., "Thermophotovoltaic Converter Performance for Radioisotope Power Systems," in proceedings of Space Technology and Applications International Forum (STAIF-2005), edited by M. El-Genk, AIP Conference Proceedings 746, American Institute of Physics, Melville, New York, 2005.

4. Flanders, L.A., Drinker, R.W., Heshmatpour, B., Moul, D.S., Fleurial, J.-P., Tuttle, K.L., "Improvements in Materials and Processes for Segmented BiTe/PbTe- BiTe/TAGS/PbSnTe Based Thermoelectric Generators," in proceedings of Space Technology and Applications International Forum (STAIF-2005), edited by M. El-Genk, AIP Conference Proceedings 746, American Institute of Physics, Melville, New York, 2005.

5. Horne, W.E., Morgan, M.D., Horne, W.P., Sundaram, V.S., "Frequency Selective Surface Bandpass Filters Applied to Radioisotope Thermophovoltaic," in proceedings of Space Technology and Applications International Forum (STAIF-2005), edited by M. El-Genk, AIP Conference Proceedings 746, American Institute of Physics, Melville, New York, 2005.

6. Ibrahim, M., Keister, J., Sun, L., Simon, T., Mantell, S., and Gedeon, D., "Assessing the Performance of Microfabricated Regenerators for Stirling Space-Power Convertor," in Proceedings of the 3rd International Energy Conversion Engineering Conference (IECEC 2005), AIAA-2005-5597, Providence, RI, 2005.

7. Lee, H., Wang, D., Wang, W., Ren, Z.F., Klotz, B., Tang, M.Y., Yang, R., Gogna, P., Fleurial, J.P., Dresselhaus, M.S., and Chen, G., "Thermoelectric Properties of Si/Ge Nano-composite," presented at International Conference on Thermoelectrics, Clemson, SC, June 19-23, 2005.

8. NASA, Amendment to NASA Research Announcement NRA 02-OSS-01-RPCT, "Research Opportunities in Space Science 2002 entitled Radioisotope Power Conversion Technology," (2002) http://research.hq.nasa.gov/code_s/nra/current/NRA-05-OSS-01-rpct/index.html, accessed November 2004.

9. Schmidt, G.R., Wiley, R.L., Richardson, R.L, "NASA's Program for Radioisotope Power System Research and Development," in proceedings of Space Technology and Applications International Forum (STAIF-2005), edited by M. El-Genk, AIP Conference Proceedings 746, American Institute of Physics, Melville, New York, 2005.

10. Wong, W.A., “Advanced Radioisotope Power Conversion Technology Research \& Development," in Proceedings of the 2nd International Energy Conversion Engineering Conference (IECEC 2004), AIAA-20045515, Providence, RI, August 16-19, 2004.

11. Wood, J.G., Carroll, C., Matejczyk, D., Penswick, L.B., and Soenker, E., "Advanced Stirling Convertor Update," in these proceedings of Space Technology and Applications International Forum (STAIF-2006), edited by M. El-Genk, AIP Conference Proceedings 746, American Institute of Physics, Melville, New York, 2006.

12. Zagorola, M.V., Izenson, M.G., Breedlove, J.J., O’Connor, G.M., Ketchum, A.C., Jetley, R.J., Simons, J.K., "An Advanced Turbo-Brayton Convertor for Radioisotope Power Systems," in proceedings of Space Technology and Applications International Forum (STAIF-2005), edited by M. El-Genk, AIP Conference Proceedings 746, American Institute of Physics, Melville, New York, 2005. 


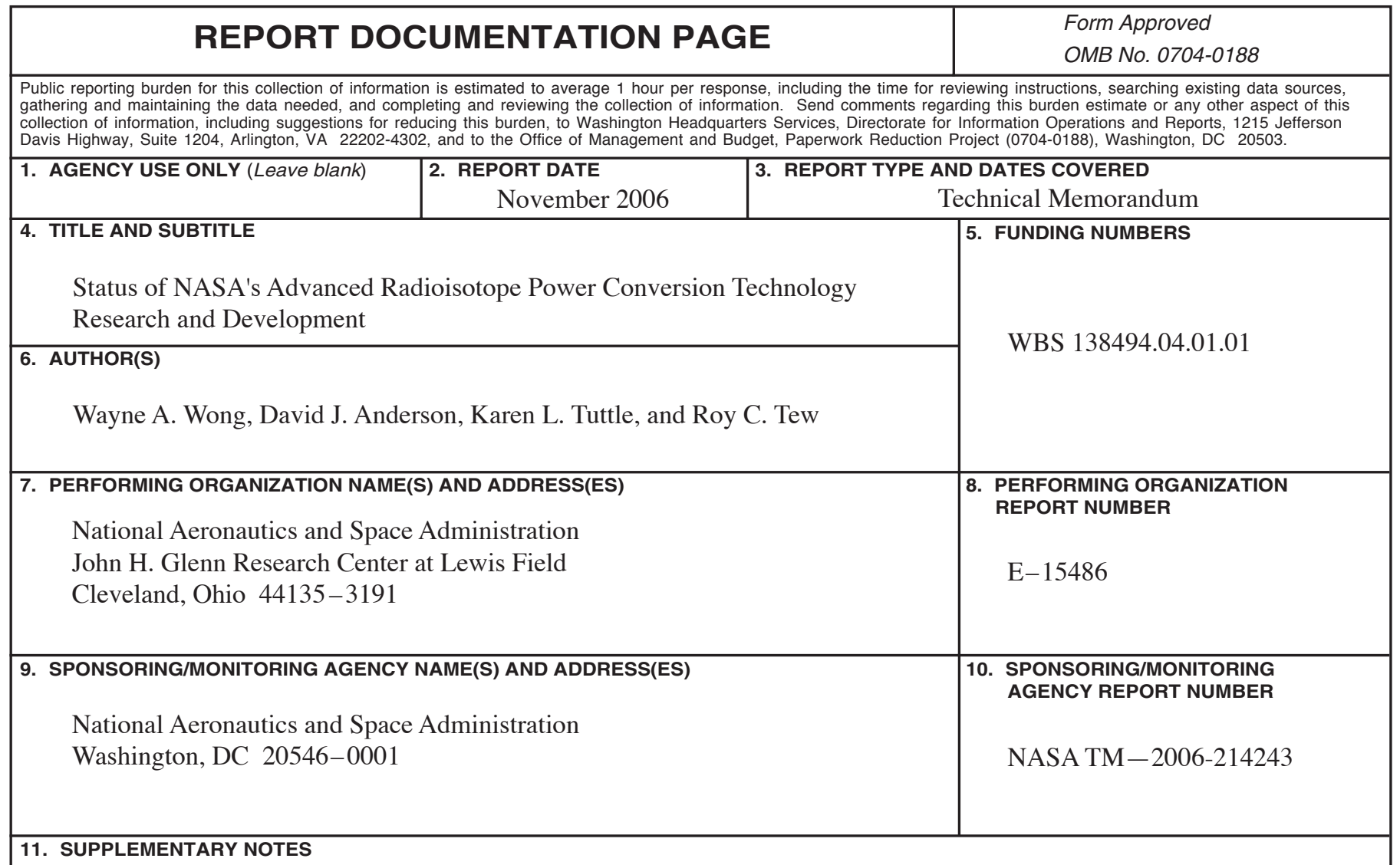

Prepared for the Space Technology and Applications International Forum (STAIF-2006) sponsored by the University of New Mexico's Institute for Space and Nuclear Power Studies (UNM-ISNPS), Albuquerque, New Mexico, February 12-16, 2006. Responsible person, Wayne A Wong, organization code RPT, 216-433-6318.

\begin{tabular}{|l|l|}
\hline 12a. DISTRIBUTION/AVAILABILITY STATEMENT & 12b. DISTRIBUTION CODE
\end{tabular}

Unclassified - Unlimited

Subject Category: 44

Available electronically at http://gltrs.grc.nasa.gov

This publication is available from the NASA Center for AeroSpace Information, 301-621-0390.

13. ABSTRACT (Maximum 200 words)

NASA's Advanced Radioisotope Power Systems (RPS) development program is funding the advancement of next generation power conversion technologies that will enable future missions that have requirements that can not be met by either the ubiquitous photovoltaic systems or by current Radioisotope Power Systems (RPS). Requirements of advanced radioisotope power systems include high efficiency and high specific power (watts/kilogram) in order to meet mission requirements with less radioisotope fuel and lower mass. Other Advanced RPS development goals include long-life, reliability, and scalability so that these systems can meet requirements for a variety of future space applications including continual operation surface missions, outer-planetary missions, and solar probe. This paper provides an update on the Radioisotope Power Conversion Technology Project which awarded ten Phase I contracts for research and development of a variety of power conversion technologies consisting of Brayton, Stirling, thermoelectrics, and thermophotovoltaics. Three of the contracts continue during the current Phase II in the areas of thermoelectric and Stirling power conversion. The accomplishments to date of the contractors, project plans, and status will be summarized.

\begin{tabular}{|c|c|c|}
\hline \multicolumn{3}{|c|}{$\begin{array}{l}\text { Advanced radioisotope power systems; Radioisotope powe } \\
\text { Energy conversion; Stirling; Thermoelectric; Regenerator }\end{array}$} \\
\hline $\begin{array}{l}\text { 17. SECURITY CLASSIFICATION } \\
\text { OF REPORT }\end{array}$ & $\begin{array}{l}\text { 18. SECURITY CLASSIFICATION } \\
\text { OF THIS PAGE }\end{array}$ & $\begin{array}{l}\text { 19. SECURITY CLASSIFICATION } \\
\text { OF ABSTRACT }\end{array}$ \\
\hline Unclassified & Unclassified & Unclassified \\
\hline
\end{tabular}

NSN 7540-01-280-5500

Standard Form 298 (Rev. 2-89)

Prescribed by ANSI Std. Z39-18 298-102 

